\title{
ANALISIS POSTUR TUBUH PEKERJA USAHA KECIL MENENGAH BATU BATA PAK BACHTIAR
}

\author{
Atika Rahma Pardosi ${ }^{(1)}$, \\ Novri Jenita Marbun ${ }^{(2)}$, \\ Adelia Alfama Zamista( ${ }^{3)}$ \\ ${ }^{1)}$ Program Studi Teknik Industri, Sekolah \\ Tinggi Teknologi Dumai \\ Jl. Utama Karya Bukit Batrem II \\ Email:atikarahmapardosi@gmail.com; \\ ovibanjarnahor@gmail.com; \\ adelia.zamista@uinib.ac.id
}

\begin{abstract}
ABSTRAK
UKM Batu Bata Pak Bachtiar merupakan usaha pembuatan batu bata secara manual oleh Pak Bachtiar yang mendukung proses pembangunan perumahan. Pekerjaan secara manual berisiko menyebabkan stres pada kondisi fisik pekerja tersebut sehingga akan mengakibatkan terjadinya cedera seperti gangguan muskuloskeletal, yaitu cedera pada bagian otot, urat syaraf, urat daging, tulang, persendian tulang, dan tulang rawan. Pemindahan material secara manual apabila tidak dilakukan secara ergonomi maka menimbulkan terjadinya kecelakaan saat bekerja. Metode REBA (rapid entire body assesment) digunakan untuk menilai postur seorang pekerja secara keseluruhan dari pergerakan seluruh bagian tubuh mulai dari leher, punggung, lengan, pergelangan tangan dan kaki pekerja. Penerapan metode dalam penelitian ini ditujukan untuk mengurangi risiko cedera yang berkaitan dengan posisi, terutama pada otot-otot skeletal dan sebagai peringatan bahwa terjadi kondisi kerja yang tidak tepat ditempat kerja. Hasil penelitian dapat disimpulkan bahwa tingkat risiko yang rendah ada 2 kegiatan yaitu pada saat kegiatan mencetak tanah liat seberat $1,5 \mathrm{~kg}$ dan melepaskan tanah liat diatas bedeng. Sedangkan tingkat risiko tinggi terdiri dari 2 kegiatan yaitu pada kegiatan mengambil tanah liat diatas bedeng dan menyusun batu bata seberat 7,5 kg.
\end{abstract}

Kata-kunci: Postur Tubuh, Muskuloskeletal, REBA

\begin{abstract}
UKM Batu Bata Pak Bachtiar is a manual brick making business by Mr. Bachtiar that supports the housing development process. Manual work risks causing stress to the physical condition of the worker so that it will result in injuries such as musculoskeletal disorders, namely injuries to the muscles, nerves, flesh veins, bones, bone joints, and cartilage. Manually transferring material if not done ergonomically, it causes accidents while working. The REBA (rapid entire body assessment) method is used to assess a worker's overall posture from the movement of all parts of the body ranging from the neck, back, arms, wrists and feet of workers. The application of the method in this study is aimed at reducing the risk of injury related to position, especially in the skeletal muscles and as a warning that there are improper working conditions at work. The results of the study can be concluded that the low risk level there are 2 activities, namely when the activity of printing clay weighing $1.5 \mathrm{~kg}$ and releasing clay on the bedeng. While the high risk level consists of 2 activities, namely on the activity of taking clay on a bedeng and arranging bricks weighing $7.5 \mathrm{~kg}$.

Keywords: Posture, Musculoskeletal, REBA.
\end{abstract}

\section{Pendahuluan}

Perkembangan industri menengah Kota Dumai sedikit demi sedikit sudah mulai terlihat. Saat ini sudah banyak industri menengah giat bersaing dan menjajakan 
produknya agar dapat dikenal dan berkompetisi. Hal ini juga disebut dengan UKM (usaha kecil menengah). Salah satu usaha kecil menengah yang mendukung proses pembangunan perumahan adalah usaha pembuatan batu bata. Bahan baku utama yang digunakan untuk proses pembuatan batu bata ini adalah air dan tanah liat.

Pekerjaan pembuatan batu bata bisa dilakukan dengan cara menggunakan mesin dan manual. Pekerjaan pembuatan batu bata secara manual dilakukan dengan dimulai dari proses pengadukan, pencetakan, pengangkatan batu bata hasil cetakan dijemur dan dibakar lalu pemindahan ke tempat lain untuk siap dijual. Pak Bachtiar memiliki UKM batu bata dengan cara pembuatannya secara manual yang berada di Kota Dumai. Pekerjaan secara manual berisiko menyebabkan stres pada kondisi fisik pekerja tersebut sehingga akan mengakibatkan terjadinya cedera seperti gangguan muskuloskeletal, yaitu cedera pada bagian otot, urat syaraf, urat daging, tulang, persendian tulang, dan tulang rawan. Pemindahan material secara manual apabila tidak dilakukan secara ergonomi maka menimbulkan terjadinya kecelakaan saat bekerja.

Penelitian ini dilakukan untuk mengetahui tingkat risiko cedera pada pekerja yang dilihat dari postur kerjanya. Metode REBA (rapid entire body assesment) adalah metode yang dapat digunakan untuk menilai postur seorang pekerja secara keseluruhan dari pergerakan seluruh bagian tubuh mulai dari leher, punggung, lengan, pergelangan tangan dan kaki pekerja. Penerapan metode dalam penelitian ini ditujukan untuk mengurangi risiko cedera yang berkaitan dengan posisi, terutama pada otot-otot skeletal dan sebagai peringatan bahwa terjadi kondisi kerja yang tidak tepat ditempat kerja.

\section{Metode Penelitian}

Populasi dalam penelitian ini adalah semua pekerja di UKM Pak Bachtiar yang berjumlah 8 orang, sedangkan sampel yang diambil berjumlah 4 orang. Teknik pengumpulan data pada penelitian ini adalah data pengamatan yang berupa postur tubuh pekerja pada saat proses membuat batu bata menggunakan kamera handphone untuk foto atau video. Kemudian data keluhan pekerja menggunakan kuesioner NBM yang terdiri dari 2 bagian, yakni bagian identitas pekerja dan bagian inti kuesioner. Diagram alir untuk penelitian ini dapat dilihat pada Gambar 1.

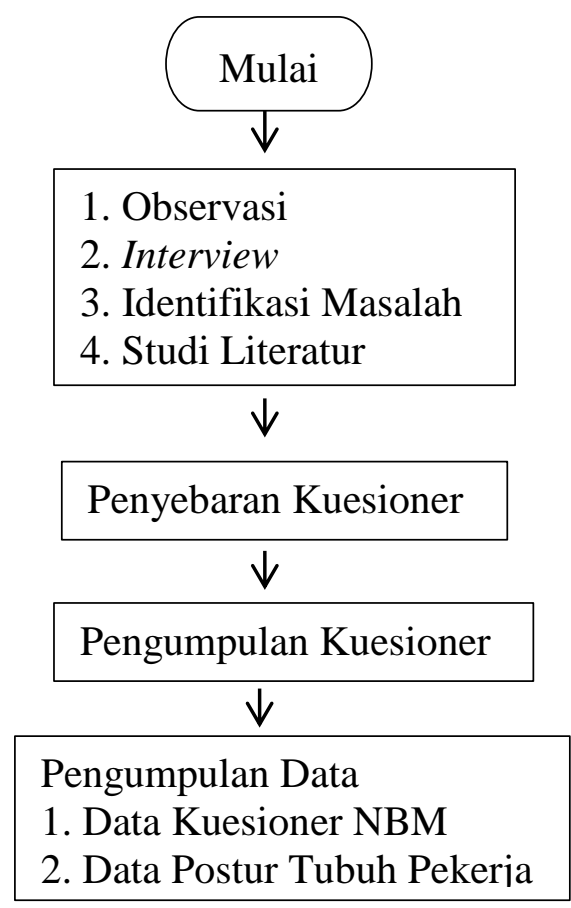




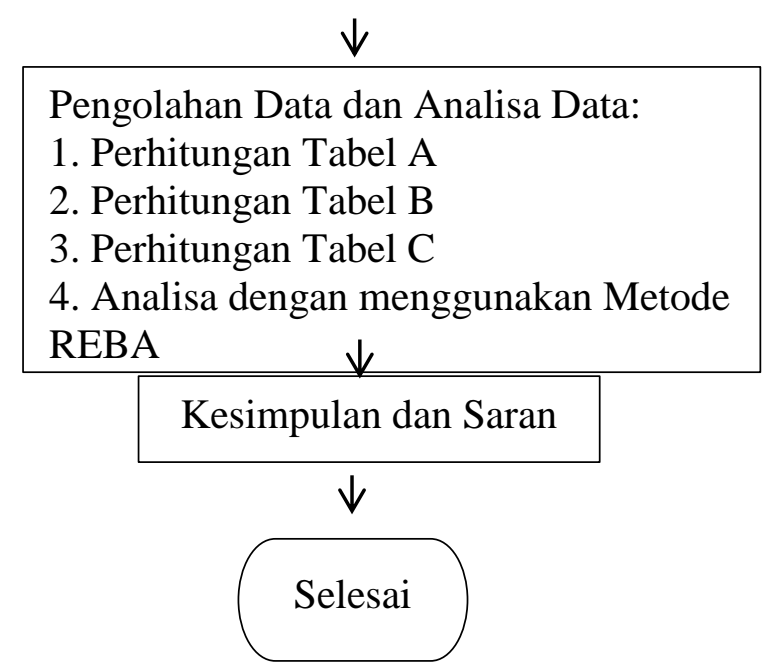

Gambar 1. Diagram Alir Penelitian

\section{Hasil dan Pembahasan}

Postur tubuh pekerja gerakannya ada 6 kegiatan, yaitu mengambil tanah liat, mencetak, mengeringkan, membawa batu bata kering, melempar batu bata dan penyusunan batu bata diatas tungku pembakaran. Postur kerja pada saat mengambil tanah dibawah bedeng dengan beban $6 \mathrm{~kg}$ oleh Alim dapat dilihat pada Gambar 2 . Penggunaan skor grup A, beban, grup B, genggaman dan aktivitas dapat dilihat pada Tabel 1.
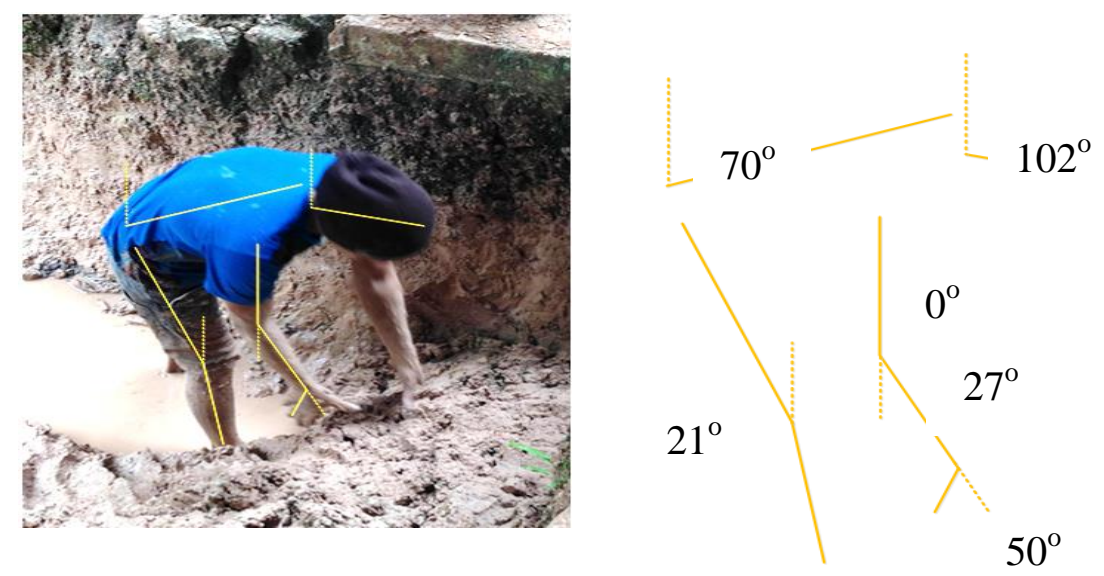

Gambar 2. Mengambil Tanah Liat dengan Beban 6 kg 
Tabel 1. Skor Pengambil Tanah Liat dibawah Bedeng Beban $6 \mathrm{~kg}$

\begin{tabular}{|c|l|l|c|}
\hline No & \multicolumn{1}{|c|}{ Kategori } & \multicolumn{1}{|c|}{ Pergerakan } & Total Skor \\
\hline 1 & Trunk & $70^{\circ}$ ke depan & 4 \\
\hline 2 & Neck & $102^{\circ}$ ke depan & 2 \\
\hline 3 & Legs & Kedua kaki menahan berat tubuh & 1 \\
\hline 4 & Load/Force & $6 \mathrm{~kg}$ & 1 \\
\hline 5 & Upper arm & Posisi normal 0 & 1 \\
\hline 6 & Lower arm & $27^{\circ}$ ke depan & 2 \\
\hline 7 & Wrist & $50^{\circ}$ extention \& menyamping & 3 \\
\hline 8 & Coupling & Good & 0 \\
\hline 9 & Activity & Perulangan & 1 \\
\hline
\end{tabular}

Tabel 1 merupakan skor yang akan digunakan untuk menghitung tingkat risiko postur kerja menggunakan metode REBA pada tabel skor A, skor B, dan skor C. Perhitungan skor REBA dapat dilihat pada Tabel 2, Tabel 3, dan Tabel 4.

Tabel 2. Penilaian Tabel Skor A

\begin{tabular}{|c|c|c|c|c|c|c|c|c|c|c|c|c|c|}
\hline \multirow{4}{*}{ Table A } & \multicolumn{13}{|c|}{ Neck } \\
\hline & & \multicolumn{4}{|c|}{1} & \multicolumn{4}{|c|}{2} & \multicolumn{4}{|c|}{3} \\
\hline & \multirow{2}{*}{ Legs } & & & & & & & & & & & & \\
\hline & & 1 & 2 & 3 & 4 & 1 & 2 & 3 & 4 & 1 & 2 & 3 & 4 \\
\hline \multirow{5}{*}{$\begin{array}{l}\text { Trunk } \\
\text { posture } \\
\text { score }\end{array}$} & 1 & 1 & 2 & 3 & 4 & 1 & 2 & 3 & 4 & 3 & 3 & 5 & 6 \\
\hline & 2 & 2 & 3 & 4 & 5 & 3 & 4 & 5 & 6 & 4 & 5 & 6 & 7 \\
\hline & 3 & 2 & 4 & 5 & 6 & 4 & 5 & 6 & 7 & 5 & 6 & 7 & 8 \\
\hline & 4 & 3 & 5 & 6 & 7 & 5 & 6 & 7 & 8 & 6 & 7 & 8 & 9 \\
\hline & 5 & 4 & 6 & 7 & 8 & 6 & 7 & 8 & 9 & 7 & 8 & 9 & 9 \\
\hline
\end{tabular}

Tabel 3. Penilaian Tabel Skor B

\begin{tabular}{|l|c|c|c|c|c|c|c|}
\hline \multirow{4}{*}{ Table B } & \multicolumn{7}{|c|}{ Lower Arm } \\
\cline { 2 - 8 } & & \multicolumn{7}{|c|}{1} & \multicolumn{3}{|c|}{2} \\
\cline { 2 - 8 } & \multirow{2}{*}{ Wrist } & \multicolumn{3}{|c|}{} & \multicolumn{3}{|c|}{} \\
\cline { 2 - 8 } & 1 & 2 & 3 & 1 & 2 & 3 \\
\hline \multirow{4}{*}{$\begin{array}{l}\text { Armer } \\
\text { Score }\end{array}$} & 1 & 1 & 2 & 2 & 1 & 2 & 3 \\
\cline { 2 - 8 } & 2 & 1 & 2 & 3 & 2 & 3 & 4 \\
\cline { 2 - 8 } & 3 & 3 & 4 & 5 & 4 & 5 & 5 \\
\cline { 2 - 8 } & 4 & 4 & 5 & 5 & 5 & 6 & 7 \\
\cline { 2 - 8 } & 5 & 6 & 7 & 8 & 7 & 8 & 8 \\
\cline { 2 - 8 } & 6 & 7 & 8 & 8 & 8 & 9 & 9 \\
\hline
\end{tabular}

Tabel 4. Penilaian Tabel Skor C

\begin{tabular}{|c|c|c|c|c|c|c|c|c|c|c|c|c|}
\hline \multirow{3}{*}{$\begin{array}{l}\text { Score A } \\
\text { (sscore } \\
\text { from table } \\
\mathrm{A}+ \\
\text { loadlforce } \\
\text { score) }\end{array}$} & \multicolumn{12}{|c|}{ Table C } \\
\hline & \multicolumn{12}{|c|}{ Score B (table B value + coupling score) } \\
\hline & 1 & 2 & 3 & 4 & 5 & 6 & 7 & 8 & 9 & 10 & 11 & 12 \\
\hline 1 & 1 & 1 & 1 & 2 & 3 & 3 & 4 & 5 & 6 & 7 & 7 & 7 \\
\hline 2 & 1 & 2 & 2 & 3 & 4 & 4 & 5 & 6 & 6 & 7 & 7 & 8 \\
\hline 3 & 2 & 3 & 3 & 3 & 4 & 5 & 6 & 7 & 7 & 8 & 8 & 8 \\
\hline 4 & 3 & 4 & 4 & 4 & 5 & 6 & 7 & 8 & 8 & 9 & 9 & 9 \\
\hline 5 & 4 & 4 & 4 & 5 & 6 & 7 & 8 & 8 & 9 & 9 & 9 & 9 \\
\hline 6 & 6 & 6 & 6 & 7 & 8 & 8 & 9 & 9 & 10 & 10 & 10 & 10 \\
\hline 7 & 7 & 7 & 7 & 8 & 9 & 9 & 9 & 10 & 10 & 11 & 11 & 11 \\
\hline
\end{tabular}




\begin{tabular}{|c|c|c|c|c|c|c|c|c|c|c|c|c|}
\hline 8 & 8 & 8 & 8 & 9 & 10 & 10 & 10 & 10 & 10 & 11 & 11 & 11 \\
\hline 9 & 9 & 9 & 9 & 10 & 10 & 10 & 11 & 11 & 11 & 12 & 12 & 12 \\
\hline 10 & 10 & 10 & 10 & 11 & 11 & 11 & 11 & 12 & 12 & 12 & 12 & 12 \\
\hline 11 & 11 & 11 & 11 & 11 & 12 & 12 & 12 & 12 & 12 & 12 & 12 & 12 \\
\hline 12 & 12 & 12 & 12 & 12 & 12 & 12 & 12 & 12 & 12 & 12 & 12 & 12 \\
\hline
\end{tabular}

Hasil dari skor $\mathrm{C}$ yang didapat adalah 6. Selanjutnya akan ditambah dengan skor aktivitas pekerja di mana skornya adalah 1, sehingga skor akhirnya adalah 7 . Tingkat risiko yang dialami oleh 4 pekerja berbeda-beda. Hasil analisis dari semua postur dapat dilihat pada Tabel 5.

Tabel 5. Hasil Analisis Tingkat Risiko Pekerja

\begin{tabular}{|c|c|c|c|c|}
\hline No & $\begin{array}{l}\text { Tingkat } \\
\text { Risiko }\end{array}$ & $\begin{array}{c}\text { Nama } \\
\text { Pekerja }\end{array}$ & Postur & Action \\
\hline \multirow[t]{2}{*}{1} & \multirow[t]{2}{*}{ Rendah } & $\begin{array}{l}\text { Bapak } \\
\text { Bachtiar }\end{array}$ & Mencetak tanah liat seberat $1,5 \mathrm{~kg}$ & \multirow{2}{*}{$\begin{array}{l}\text { Mungkin } \\
\text { diperlukan }\end{array}$} \\
\hline & & Sandi & Melepaskan tanah liat diatas bedeng & \\
\hline \multirow{12}{*}{2} & \multirow{12}{*}{ Sedang } & Alim & Mengambil tanah liat dibawah bedeng & \multirow{12}{*}{ Diperlukan } \\
\hline & & Alim & Mengangkat tanah liat dibawah bedeng & \\
\hline & & Alim & Melepaskan tanah liat dibawah bedeng & \\
\hline & & Sandi & Menunggu tanah liat diatas bedeng & \\
\hline & & $\begin{array}{l}\text { Bapak } \\
\text { Bachtiar }\end{array}$ & Mengambil tanah liat seberat $1,5 \mathrm{~kg}$ & \\
\hline & & $\begin{array}{l}\text { Bapak } \\
\text { Bachtiar }\end{array}$ & $\begin{array}{l}\text { Menyusun batu bata secara rapat seberat } \\
1,5 \mathrm{~kg}\end{array}$ & \\
\hline & & $\begin{array}{l}\text { Bapak } \\
\text { Bachtiar }\end{array}$ & $\begin{array}{l}\text { Menyusun batu bata secara vertikal dan } \\
\text { berjarak seberat } 1,5 \mathrm{~kg}\end{array}$ & \\
\hline & & $\begin{array}{l}\text { Bapak } \\
\text { Bachtiar }\end{array}$ & Mengangkat batu bata dengan berat $6 \mathrm{~kg}$ & \\
\hline & & $\begin{array}{l}\text { Bapak } \\
\text { Bachtiar }\end{array}$ & $\begin{array}{l}\text { Membawa batu bata menggunakan } \\
\text { angkong dengan beban } 45 \mathrm{~kg}\end{array}$ & \\
\hline & & $\begin{array}{l}\text { Bapak } \\
\text { Bachtiar }\end{array}$ & Mengambil batu bata kering & \\
\hline & & $\begin{array}{l}\text { Bapak } \\
\text { Bachtiar }\end{array}$ & $\begin{array}{l}\text { Melempar batu bata ke atas tungku } \\
\text { pembakaran }\end{array}$ & \\
\hline & & Tugiran & Menyusun batu bata satu persatu & \\
\hline \multirow[b]{2}{*}{3} & \multirow[b]{2}{*}{ Tinggi } & Sandi & Mengambil tanah liat diatas bedeng & \multirow{2}{*}{$\begin{array}{l}\text { Diperlukan } \\
\text { secepatnya }\end{array}$} \\
\hline & & $\begin{array}{l}\text { Bapak } \\
\text { Bachtiar }\end{array}$ & Menyusun batu bata seberat $7,5 \mathrm{~kg}$ & \\
\hline
\end{tabular}

Tabel 5 merupakan hasil analisis postur kerja para pekerja di UKM Bapak Bachtiar menggunakan metode REBA. Hasil dari analisis untuk postur pada saat kegiatan pengambilan tanah liat, mencetak, mengeringkan, pengangkatan batu bata kering, melempar batu bata dan penyusunan batu bata diatas tungku pembakaran dapat dievaluasi dengan menentukan tindakan sesuai dengan skor yang sudah didapat. Level risiko yang didapatkan adalah rendah, sedang, dan tinggi. Level risiko rendah diberikan perubahan postur kerja. Level risiko sedang dibutuhkan investigasi yang lebih jauh dan perubahan postur kerja secepatnya. Sedangkan level risiko tinggi harus dilakukan investigasi dan adanya implementasi berupa perubahan postur kerja. 


\section{Kesimpulan}

Kesimpulan dari tugas akhir ini ialah tingkat risiko yang dialami 4 pekerja di UKM Bapak Bachtiar menggunakan metode REBA adalah rendah, sedang dan tinggi. Tingkat risiko yang rendah ada 2 kegiatan yaitu pada saat kegiatan mencetak tanah liat seberat $1,5 \mathrm{~kg}$ dan melepaskan tanah liat diatas bedeng. Tingkat risiko sedang terdiri dari 12 kegiatan yaitu pada kegiatan mengambil tanah liat dibawah bedeng, mengangkat tanah liat dibawah bedeng, melepaskan tanah liat dibawah bedeng, menunggu tanah liat diatas bedeng, mengambil tanah liat seberat $1,5 \mathrm{~kg}$, menyusun batu bata secara rapat seberat $1,5 \mathrm{~kg}$, menyusun batu bata secara vertikal dan berjarak seberat $1,5 \mathrm{~kg}$, mengangkat batu bata dengan berat $6 \mathrm{~kg}$, membawa batu bata menggunakan angkong dengan beban $45 \mathrm{~kg}$, mengambil batu bata kering, melempar batu bata ke atas tungku pembakaran dan menyusun batu bata satu persatu. Tingkat risiko tinggi terdiri dari 2 kegiatan yaitu pada kegiatan mengambil tanah liat diatas bedeng dan menyusun batu bata seberat $7,5 \mathrm{~kg}$.

\section{Saran}

Saran yang dapat diusulkan adalah:

1. Tingkat risiko tertinggi terjadi pada saat kegiatan mengambil tanah liat diatas bedeng dengan bebannya $6 \mathrm{~kg}$ dan pada saat menyusun batu bata bebannya 7,5 kg sebaiknya saat melakukan kegiatan tersebut kurangi beban dari tanah liat tersebut agar badan tidak cepat lelah ataupun sakit.

2. Saat bekerja sebaiknya posisi tubuh pekerja diminimalisir dari sikap kerja membungkuk, leher mendongak terlalu ke depan maupun ke belakang, agar mengurangi risiko sakit pada leher dan punggung.

3. Sebaiknya dalam pekerjaan pembuatan batu bata ini ditambah tenaga kerjanya karna dalam pekerjaan ini yang paling banyak dilakukan oleh Bapak Bachtiar sehingga tingkat risiko bekerja dari Bapak Bachtiar ini paling dominan dan cenderung lebih sering merasa kesakitan pada tubuhnya daripada ketiga pekerja lainnya.

4. Untuk jarak bedeng dari bawah ke atas lebih bagus dibuat jarak tempatnya berdekatan sekitar 1 meter agar pada saat mengambil tanah liat posisi badan tidak terlalu membungkuk.

\section{Daftar Pustaka}

Astari, G.C.R., 2013, Analisa Tingkat Risiko Ergonomi Berdasarkan Aspek Pekerjaan pada Pekerja Laundry Sektor Usaha Informal di Kecamatan Ciputat Timur Kota Tangerang Selatan Tahun 2012, Skripsi, Sarjana Kesehatan Masyarakat, UIN syarif Hidayatullah, Jakarta.

Azmi, Fitra, dan Suroso, M., (2021), Penerapan Data Antropometri Dalam Perancangan Alat Pengupas Sabut Kelapa Ekonomis, Jurnal ARTI (Aplikasi Rancangan Teknik Industri), VOL.16 NO 1 (2021) Desember 2020 - Mei 2021, Hal: 94-99

Iridiastadi, H., dan Yassierli, 2014, Ergonomi Suatu Pengantar, PT Remaja Rosdakarya, Bandung. 
Joanda, A.D., dan Suhardi, B., 2017, Analisis Postur Kerja dengan Metode REBA untuk Mengurangi Resiko Cedera pada Operator Mesin Binding, Jurnal Teknik Industri, ISSN: 2579-6429.

Mutmainah, dan Sari, M., 2018, Perancangan Alat Bantu Alat Pemantau Area Produksi yang Ergonomis dengan Metode Value Engineering (Studi Kasus PT BT), Jurnal Integrasi Sistem Industri, Vol. 5, No 1, ISSN: 2355-2085.

Nur, R.F., Lestari, E.R., dan Mustaniroh, S.A., 2016, Analisis Postur Kerja pada Stasiun Pemanenan Tebu dengan Metode OWAS dan REBA, Jurnal Teknologi dan Manajemen Agroindustri, Vol. 5 No. 1 : 39-45, ISSN 2252-7877.

Rinawati, S., dan Romadona., 2016, Analisis Risiko Postur Kerja Pada Pekerja Di Bagian Pemilahan dan Penimbangan Linen Kotor Rs. X, Jurnal Teknik Industri, Vol. 1, No 1, ISSN 2541-5727.

Setiorini, A., Musyarofah, S., dan Kendal, B., 2017, Analisis Postur Kerja Dengan Metode Reba dan Gambaran Keluhan Subjektif Musculoskeletal Disorders (Msds), Jurnal Kesehatan, Vol 1, ISSN 1979-7621.

Supriyanto, 2011, Perancangan Postur Kerja pada Pekerja Bagian Pencucian dan Penggilingan Kedelai dengan Pendekatan REBA untuk Mengurangi Risiko MSDs, Skripsi, Teknik Industri, Universitas Sebelas Maret, Surakarta. 